

\section{Sumário}

Crimes de responsabilidade do Presidente da República...............................................14 Carlos Ayres Britto

REFLEXÕES SOBRE O FUTURO DO ESTADO CONSTITUCIONAL MODERNO .22

Cesar Luiz Pasold, Gabriel Real Ferrer e Paulo Márcio Cruz

CONTRATOS PÚBLICOS Y MERCADO GLOBAL: UN ABORDAJE DESDE EL DERECHO ADMINISTRATIVO DEL SIGLO XXI.

Bruno Ariel Rezzoagli

CONTRATOS ADMINISTRATIVOS: CONCEITO E CRITÉRIOS DISTINTIVOS

Carlos Bastide Horbach

Os incentivos econômicos à compra de colhedoras pelo Pronaf-Mais alimentos para os PRODUtORES DE ARROZ IRRIGAdo do Rio GRANDE do Sul.

João Mairton Moura de Araújo, Mário Conill Gomes e André Carraro

LiMitAÇõES À EXTRAFISCALIDADE APLICÁVEIS AO FATOR ACIDENTÁRIO DE PREVENÇÃo - FAP...84 Daniel de Magalhães Pimenta

DesConstruindo A INEFICÁCIA DOS DIREITOS SOCIAIS: POR UMA RECONSTRUÇÃO DOS DIREITOS SOCIAIS DEMOCRÁTICA, PARTICIPATIVA E TRANSNACIONAL 106

Daniela Lopes de Faria, Christian Norimitsu Ito e Inês Moreira da Costa

DIREITO PROCESSUAL DE GRUPOS SOCIAIS ATUAL: ENTRE O ATIVISMO JUDICIAL E O GARANTISMO PROCESSUAL

Jefferson Carús Guedes

Políticas públicas, mínimo existencial e Poder Judiciário: a Questão do direito À moRADIA

Diogo de Calasans Melo Andrade 
BENEFíCIOS DE RENDA MÍNIMA COMO UM DIREITO FUNDAMENTAL: ACESSO À JUSTIÇA E INCLUSÃO

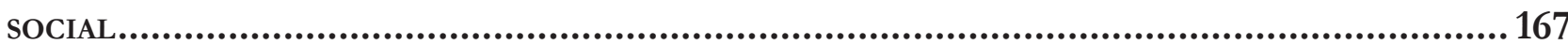

Pedro Bastos de Souza

DesenVolvimento humano SUSTENTÁVEl E ERRADiCAÇão dA POBREZA EXTREMA: UMA ANÁLISE

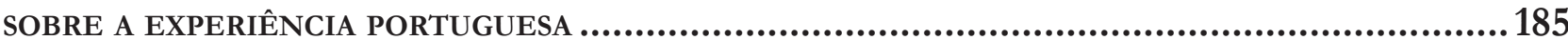

Veyzon Campos Muniz

A AÇÃO POPUlAR AMBIENTAL COMO FORMA DE PARTICIPAÇÃO SOCIAL NA DEFESA DO MEIO AMBIENTE ....203 Luciano Marcos Paes e Paulo Roberto Polesso

Direito PENAL AMBIENTAL COMO TUTEla de SUSTENTAÇÃo À ATUAÇÃo ADMINISTRATIVA E CIVIL nos Estados Unidos da AMÉrica E no Japão ...................................................214

Luiz Gustavo Gonçalves Ribeiro e Lorena Machado Rogedo Bastianetto

ConstruÇão Social do PRoJeto POlOS DE PRODUÇÃo DE BIODIESEL NO CONTEXTO do PNPB: UMA ANÁLISE PERCEPTIVA ......................................................................230

Érika Cristine Silva, Maria das Dores Saraiva de Loreto, Haudrey Germiniani Calvelli e Ronaldo Perez

A CORRElaÇão entre doenÇas respiratórias e o inCremento das Queimadas em Alta Floresta e Peixoto de Azevedo, norte do Mato Grosso - Amazônia Legal ....................246 Lilian Rose Lemos Rocha e Christopher William Fagg

Políticas públicas, agricultura familiar e Cidadania no Brasil: o caso do PRONAF ...... 256 Edir Vilmar Henig e Irenilda Ângela dos Santos

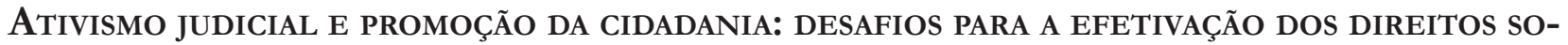
CIAIS CONSTITUCIONALIZADOS

Gerardo Clésio Maia Arruda, Adriana Rossas Bertolini e Jânio Pereira Cunha 


\title{
Políticas públicas, mínimo existencial e Poder Judiciário: a questão do direito à moradia*
}

\author{
Public policy, existential minimum and \\ Judiciary: matter of the right to housing
}

Diogo de Calasans Melo Andrade**

\section{Resumo}

O programa minha casa minha vida (PMCMV) é uma política púbica de moradia que dá impulso às ações do Estado no sentido de concretizar o direito à moradia. Ocorre que, segundo pesquisas trazidas no decorrer deste artigo, nem sempre se concede uma moradia digna para todos, não se chegando a cidadania plena. Assim, resta a seguinte indagação: pode o Poder Judiciário interferir nas políticas públicas de moradia? Por outro lado, o Estado/ Poder Executivo traz como limite a não interferência o mínimo existencial, a reserva do possível e a separação dos poderes, a tese que, como será demonstrado, não parece razoável e apropriada. Defende-se, aqui, que a moradia é o núcleo essencial de um direito fundamental, ou seja, o mínimo existencial que deve ser realizado pelo Estado. Por fim, argumenta-se que, na falta de programas de governo ou políticas públicas de moradia eficazes, por parte do Poder Executivo, resta ao Poder Judiciário intervir em tais políticas, com as funções de controle e de fiscalização, com um único fim: concretizar o direito social à moradia.

Palavras-chaves: Políticas públicas. Moradia. Poder Judiciário.

\section{Abstract}

The Minha casa Minha vida program (MCMV) is a pubic housing policy that propels the State's actions in order to realize the right to housing. It turns out that, according to surveys brought within that article, if not always provides decent housing for everyone, not reaching full citizenship. Thus, there remains the following question: can the judiciary interfere in public housing policies? On the other hand, the State/ Executive Branch, brings as limit the non interference in the minimum existencial, the booking of possible and the separation of powers, thesis that, as will be demonstrated, do not seem reasonable or appropriate. It is argued, here, that housing is the essential core of a fundamental right, that means, the existential minimum that must be done by the state. Finally, it is argued that in the absence of public governmental or public policy programs of effective housing, by the Executive Branch, left to the courts intervene in such policies, controlling and supervising, with a sole purpose: achieving the social right to housing. radentes (2002). Mestre em Direito pela Univer-
sidade Federal de Sergipe (2013). Doutorando em Direito na Universidade Presbiteriana Mackenzie.E-mail:contato@diogocalasans.com

Recebido em 07/12/2015

Aprovado em 14/12/2015

** Bacharel em Direito pela Universidade Ti- 
Keywords: Public policy. Housing. Executive branch.

\section{As políticas públicas de moradia No Brasil}

O CNPq junto com o Ministério das Cidades, lançou em 2012, edital de pesquisa para avaliar o Programa Minha Casa Minha Vida (PMCMV), do qual resultaram 11 equipes contempladas que formaram a "Rede Cidade e Moradia" e avaliaram empreendimentos de 22 municípios em 6 estado: Pará, Ceará, Rio Grande do Norte, Minas Gerais, Rio de Janeiro e São Paulo, e concluíram que: a) como são as construtoras - em sua relação com a Caixa - que definem o projeto e sua localização, tem prevalecido no programa padrão de produção com fortíssima homogeneização das soluções de projeto arquitetônico e urbanístico e das técnicas construtivas, independentemente das características físicas dos terrenos ou das condições bioclimáticas locais; b) os Municípios permitem a construção dos empreendimentos em localizações mais baratas, como em zonas rurais englobadas por alterações nos perímetros urbanos, que reproduzem padrão de cidade segregada e sem urbanidade, pois são mal servidas por transporte, infraestrutura ou oferta de serviços urbanos adequados ao desenvolvimento econômico e humano; c) os processos de seleção da demanda feito por meio de cadastro das prefeituras nem sempre são transparentes; d) programa habitacional que atende, prioritariamente, aos interesses do setor privado, sem vínculos necessários com uma política urbana e fundiária, que estima o aumento dos preços dos imóveis na cidade e tem gerado péssimas inserções urbanas e segregação social, e) o programa baseia-se numa produção padronizada e em larga escala, desarticulada das realizadas locais, mal inserida e isolada da cidade, com base em modelo de propriedade privada condominial ${ }^{1}$.

Assim, percebe-se que o PMCMV possui série de problemas e mesmo concedendo grande número de habitações, segundo a citada pesquisa, essas moradias não são dignas, o que gera a falta de uma cidadania plena, uma vez que, sem moradia, não se pode falar em cidadania. Esse PMCMV possui sérios problemas e não atinge toda a população sem moradia do Brasil, sendo necessário, em primeiro lugar, análise das políticas públicas de moradia, pois, para a efetivação da cidadania e dos direitos sociais, é necessário que o Estado, juntamente com a sociedade civil organizada, realize políticas públicas eficazes e esses direitos sociais possuem enfoque prestacional, uma obrigação de fazer do Estado.

Ainda sobre o tema habitação, existem dois grandes problemas quando analisamos os casos práticos, um em relação à falta de clareza e informação do governo a respeito dos programas de habitação, que se limita a dizer o custo, sem fiscalização; o outro é a perda do controle da situação para que não haja caos. Assim, percebe-se que temos processos, mas não se tem a continuidade da melhoria e acompanhamento dos projetos implementados².

O tema políticas públicas é, inicialmente, da ciência política e da administração pública. Mas, para estudar as políticas públicas, faz-se essencial estudar as instituições jurídicas, o processo político de tomada de decisões e a legitimidade. Assim, para uma política pública ser considerada legítima, esta deve fundar-se na lei. Os desafios para implementação das políticas públicas são jurídicos, econômicos e, principalmente, polí-

1 RUfINO, Maria Beatriz Cruz; SHIMBO, Lúcia Zanin; AMORE, Caio Santo (Org.). Minha casa... e a cidade? Avaliação do programa minha casa minha vida em seis estados brasileiros. Rio de Janeiro: Letra capital, 2015. p. 419-422.

2 Para isso, o senado investiga, periodicamente, o impacto dos programas governamentais em relação aos objetos para os quais eles foram criados, criando resolução que procura: contrastar o que aconteceu após a intervenção (ou a omissão) do Poder Público com o que teria ocorrido em um cenário contrafatual. Qualquer é a essência da atividade de avaliação, que tem, basicamente, três finalidades não excludentes entre si: a) identificar os resultados que podem ser atribuídos à intervenção; b) compreender os mecanismos que determinam seu sucesso (ou fracasso), em relação aos objetivos preestabelecidos; e c) investigar a eficiência da intervenção. Na dimensão resultado, o enfoque consiste em medir os efeitos da intervenção. FREITAS, Igor Vilas Boas. Avaliação de politica pública no Senado Federal: proposta de abordagem. Brasília: Senado Federal, 2013. Disponível em: < https://www12.senado. leg.br/publicacoes/estudos-legislativos/tipos-de-estudos/outras-publicacoes/avppsf/avaliacao-de-politicas-publicas-no-senadofederal-1>. Acesso em 10 set. 2015. 
ticos. As decisões do Estado sobre Políticas Públicas, a depender da hipótese, são exercidas e realizadas por meio do Direito. Já o alcance de uma política pública é supraindividual, uma vez que envolve a coletividade, com demandas expectativas comuns.

Diferentemente das leis, as políticas públicas não são gerais e abstratas, são específicas e buscam a realização de objetivos determinados. Elas atuam de forma complementar, preenchendo os espaços normativos e concretizando os princípios e regras, com vista a objetivos determinados. Correspondem, no plano jurídico, as diretrizes, normas de um tipo especial, rompendo as amarras dos atributos de generalidade e abstração - que extremam as normas dos atos jurídicos, estes concretos, para dispor sobre matérias contingentes 3 .

O estado da arte na área de políticas públicas significa o mapa de como a literatura clássica resume a política pública como o campo do conhecimento que busca, ao mesmo tempo, "colocar o governo em ação" e/ou analisar essa ação (variável independente) e, quando necessário, propor mudança no rumo ou curso dessas ações (variável dependente). A formulação de políticas públicas constitui-se no estágio em que os governos democráticos traduzem seus propósitos e plataformas eleitorais em programas e ações que produzirão resultados ou mudanças no mundo real ${ }^{4}$.

Sobre a definição de políticas públicas, Bucci ${ }^{5}$ conceitua esse termo como um programa ou quadro de ação governamental, porque consiste em conjunto de medidas articuladas (coordenadas) cujo escopo é dar impulso, isto é, movimento à máquina do governo, no sentido de realizar algum objetivo de ordem pública ou na ótica dos juristas, concretizar o direito. A doutrina traz outros conceitos para políticas públicas ${ }^{6}$

Assim, as políticas públicas partem do Estado e têm como finalidade a concretização de um direito. Outro ponto importante consiste em analisar quais são os elementos e as etapas que compõem o ciclo das políticas públicas e a forma como estão sendo ou não articulados. Para o processo de definição e implementação das políticas públicas, é necessário analisar uma série de atividade e etapas distintas, dentre as quais podemos destacar: (a) identificação dos problemas e demandas a serem atacadas para a definição das prioridades a serem decididas junto aos formuladores de políticas públicas; (b) formulação de propostas concretas entre diferentes opções de programas a serem adotados; (c) implementação propriamente dita da política, com a criação da estrutura necessária e observância da burocracia existência, gasto de recurso e aprovação de leis; (d) avaliação de recursos da política por meio da verificação do resultado e impactos da política, para que se possa aferir se ela realmente funciona ou não; (e) fiscalização e controle da execução da política por meio da atuação da sociedade civil, dos Tribunais de Contas e do Ministério Público?

De mais a mais, Bucci, em outra obra, propôs examinar o fenômeno governamental, enquanto manifestação juridicamente disciplinada, em três planos de aproximação: macro, meso e micro institucional. Há, no plano macroinstitucional, as decisões políticas fundamentais, a "grande política", bem como os rumos do

3 BUCCI, Maria Paula Dallari. O conceito de política pública em direito. In: (Org.). Politicas Públicas: reflexões sobre o conceito jurídico. São Paulo: Saraiva, 2006. p. 25-27.

4 SOUZA, Celina. Políticas públicas: uma revisão da literatura. Revista Sociologias, Porto Alegre, v. 8, n. 16, p. 20-45, jul./dez. 2006 . p. 26 5 BUCCI, Maria Paula Dallari. O conceito de política pública em direito. In: conceito jurídico. São Paulo: Saraiva, 2006. p. 14.

6 Política como uma atividade, isto é, conjunto organizado de normas e atos tendentes à realização de objetivo determinado. COMPARATO, Fábio Konder. Ensaio sobre o juízo de constitucionalidade de políticas públicas. In: MELLO, Celso Antonio Bandeira de (Org.). Estudos em homenagem a Geraldo Ataliba. São Paulo: Malheiros, 1997. p. 39-48. p. 97. Compreende políticas públicas como uma atuação do Estado no sentido de reduzir os efeitos negativos da descontinuidade administrativa, assim como para potencializar os recursos disponíveis. MATSUMOTO, Meggie Iara; BARBOSA, Claudia Maria. A legitimidade do poder judiciário na condução de políticas públicas para a realização de direito fundamentais. In: PAMPLONA, Danielle Anne (Coord). Politicas públicas: elementos para alcance do desenvolvimento sustentável. Curitiba: Juruá, 2012. Concluímos, portanto, que as políticas públicas constituem os mecanismos estatais de efetivação dos direitos fundamentais, mediante a satisfação espontânea dos bens da vida por eles protegidos. O Estado, como sujeito passivo da obrigação, as satisfaz por meio da atuação concreta das formas de expressão do poder estatal. CANELA JUNIOR, Osvaldo. Controle judicial de politicas públicas. São Paulo: Saraiva, 2011. p. 59.

7 DUARTE, Clarice Seixas. Para além da judicialização: a necessidade de uma nova forma de abordagem das políticas públicas. In: SMANIO, Gianpaolo Poggio; BERTOLIN, Patrícia Tuma Martins; BRASIL, Patrícia Cristina (Org.). O direito na fronteira das políticas públicas. São Paulo: Páginas e Letras, 2015. p. 26. 
planejamento de longo prazo. No plano meso institucional, da "média política", os arranjos institucionais, que desenham a ação governamental racionalizada, agregando e compondo os elementos disponíveis, em uma direção determinada, tornada previsível, com base em regra e institucionalização jurídica, que define as situações a serem experimentadas em operações futuras, resultando na reiteração da ação. Finalmente, há a ação governamental, nas suas menores unidades, microinstitucional, a chamada "pequena política" no desenrolar do processo político que leva a formação e o desenvolvimento das políticas públicas, a decisão e as iniciativas pertinentes, além das decisões judiciais, nas hipóteses de conflito. Essa dimensão é aquela que sobressai o papel dos indivíduos ${ }^{8}$.

Por outro lado, é importante diferenciar planejamento do plano, uma vez que o planejamento coordena, racionaliza e dá unidade de fins à atuação do Estado, diferenciando-se de uma intervenção conjuntural ou casuística. O plano é a expressão da política geral do Estado, é mais que um programa, é um ato de direção política, pois determina a vontade estatal por meio de um conjunto de medidas coordenadas, não podendo limitar-se à mera enumeração de reivindicações. O planejamento, embora possua conteúdo técnico, é um processo político, especialmente nas sociedades que buscam a transformação das estruturas econômicas e sociais. Surgem planos, mas não há planejamento. Um plano de desenvolvimento requer o planejamento da Administração Pública. O plano sem planejamento é uma formulação racional de ideias, mas sem nenhuma efetividade prática. O planejamento é o processo e o plano é a concretização9. Assim, para que exista a efetividade prática de um direito, faz-se necessário plano com o seu respectivo planejamento.

Existe diferença entre política de Estado e política de Governo. Na primeira o horizonte temporal é medido em décadas, políticas constitucionalizadas e, em relação à segunda, as políticas se realizam como parte de um programa maior, com suporte infralegais ${ }^{10}$. Para a referida autora, não se reconhece à noção de política pública o sentido de uma categoria nova no direito.

Por fim, Bucci traz o quadro referência que sintetiza o caráter sistemático que articula os elementos mais importantes que integram a política pública e indica os seguintes elementos: 1) Nome oficial do programa de ação; 2) Gestão governamental; 3) Base normativa; 4) Desenho jurídico-institucional; 5) Agentes governamentais; 6) Agentes não governamentais; 7) Mecanismos jurídicos de articulação; 8) Escala e público-alvo; 9) Dimensão econômico-financeira do programa; 10) Estratégica de implantação; 11) Funcionamento efetivo do programa e 12) Aspectos do desenho jurídico-institucional ${ }^{11}$.

Em relação ao nosso tema moradia, aplicando o quadro de referência ao PMCMV temos os seguintes elementos que integram a política pública: 1) a nome oficial do programa é Programa Minha Casa Minha Vida (PMCMV), 2) a gestão é da União, 3) a base normativa é a Lei 11.977/09, 4) Programa Nacional de Habitação Urbana e Rural, 5) os agentes governamentais são a União, Estados, Municípios e Distrito Federal, 6) os agentes não governamentais são os beneficiários, cooperativas habitacionais, associações de moradores, fundações, organizações da sociedade civil, 7) mecanismos jurídicos de articulação, 8) famílias com renda de até $\mathrm{R} \$ 4.650,00,9)$ a dimensão econômico-financeira é de $\mathrm{R} \$ 16.500 .000 .000$,00 para o fundo de arrendamento residencial-FAR e $\mathrm{R} \$ 500.000 .000,00$ para o fundo de desenvolvimento social-FDS, 10) estratégia de implantação, 11) funcionamento efetivo do programa e 12) desenho jurídico-institucional.

Não é o objetivo deste artigo analisar, profundamente, o PMCMV, uma vez que, para isso, faz-se necessário trabalho com pesquisa de dados estatísticos, pesquisa de campo, revisão da literatura e, provavaelmente,

8 BUCCI, Maria Paula Dallari. Fundamentos para uma teoria jurídica de politicas públicas. São Paulo: Saraiva, 2013. p. 43.

9 BERCOVICI, Gilberto. Planejamento e políticas públicas: por uma nova compreensão do papel do Estado. In: BUCCI, Maria Paula Dallri (Org.). Políticas Públicas: reflexões sobre um conceito jurídico. São Paulo: Saraiva, 2006. p. 143-161. p. 145-148.

10 BUCCI, Maria Paula Dallari. O conceito de política pública em direito. In: (Org.). Políticas Públicas: reflexões sobre o conceito jurídico. São Paulo: Saraiva, 2006. p. 12.

11 BUCCI, Maria Paula Dallari. Quadro de referência de uma política pública: primeiras linhas de uma visão jurídico-institucional. In: SMANIO, Gianpaolo Poggio; BERTOLIN, Patrícia Tuma Mantins; BRASIL, Patricia Cristina (Org.). O direito na fronteira das políticas públicas. São Paulo: Páginas e Letras, 2015. p. 9-11. 
anos de pesquisa para que se possa detectar a situação concreta do programa. No presente artigo científico, o método escolhido foi o sintético ${ }^{12}$, além da revisão bibliográfica descritiva, exploratória em que serão analisados leis e normas, relatórios técnicos, livros, artigos, teses e dissertações, além da busca em sites do Governo e do Poder Judiciário.

Assim, após a análise das políticas públicas voltadas à moradia no Brasil, podemos perceber que nem sempre esse direito é concretizado, o que faz surgir o seguinte questionamento: quais são os limites para o Poder Judiciário interferir nas políticas públicas criadas pelo Executivo? Esses limites são o mínimo existencial, a reserva do possível e a separação dos poderes, objetos do próximo tópico desde artigo.

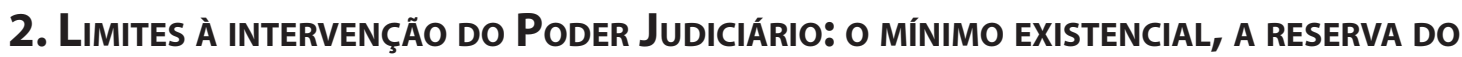 POSSÍVEL E A SEPARAÇÃo dOS PODERES}

O que podemos fazer para mudar esse quadro relacionado à falta de habitação? Esse direito fundamental à moradia é uma necessidade humana vital, biológica e indispensável para uma vida digna. Não existe vida digna sem moradia também digna. Uma das funções da propriedade urbana é a consecução da moradia, pois o direito à moradia é um direito ao acesso à propriedade da habitação, que, por meio do mercado imobiliário, chegamos à propriedade.

Os constitucionalistas tratam esse direito como um direito humano, de segunda geração ou dimensão e como um direito fundamental social, já os civilistas como um direito real de conteúdo patrimonial, é o que diz Milagres ${ }^{13}$ quando entende que: "na visão constitucional, o direito à moradia configura direito fundamental de segunda geração ou dimensão, de conteúdo mínimo, objeto de implementação gradativa mediante a realização de políticas públicas".

Já Souza defende ser o direito à moradia um exercício que deve ser protegido e efetivado pelo Estado:

$\mathrm{O}$ direito à moradia torna-se um exercício que deve ser naturalmente protegido e efetivado pelo Estado, independentemente de norma infraconstitucional ou constitucional, já que decorre de um estado de necessidade do indivíduo e, em contrapartida, de um dever legal assumido pelo Estado Brasil, inclusive perante organizações internacionais ${ }^{14}$.

O direito à moradia não se resume a programas habitacionais, mas às condições de habitabilidade proporcionadas pelos centros urbanos e que a impossibilidade de um pleno exercício deste impõe custo muito elevado para a sociedade e, por conseguinte, demanda efetiva sobre o Poder Público ${ }^{15}$.

Assim, surge como primeiro limite à intervenção do judiciário nas políticas públicas a garantia do mínimo existencial ${ }^{16}$, considerado um direito às condições mínimas de existência humana digna que exige prestações positivas por parte do Estado; o segundo limite é a razoabilidade, que mede-se pela aplicação do princípio da proporcionalidade, que significa a busca do justo equilíbrio entre os meios empregados e os fins a serem alcançados; e o terceiro limite é a reserva do possível, conhecida como disponibilidade financeira,

12 Sintetizar os argumentos implica construir o sumário, ou melhor, dividir as partes de um todo com o espírito de resumi-las. Se apoia na ideia de uma divisão lógica dos argumentos ao apresentar e construir um texto jurídico. MONEBHURRUN, Nitish. Manual de metodologia jurídica: técnicas para argumentar em textos jurídicos. São Paulo: Saraiva, 2015.

13 MILAGRES, Marcelo de Oliveira. Direito à moradia. São Paulo: Atlas, 2011. p. 63.

14 SOUZA, Sergio Iglesias Nunes de. Direito à moradia e de habilitação: análise comparativo e seu aspecto teórico e prático com os direitos da personalidade. 3. ed. São Paulo: Revista dos Tribunais, 2013. p. 213.

15 MUKAI, Toshio. Temas de direito urbanístico e ambiental. Belo Horizonte: Fórum, 2007. p. 66.

16 Compreendamos como núcleo essencial de um direito fundamental o mínimo necessário a ser realizado pelo Estado para o reconhecimento do próprio valor que se almejou resguardar juridicamente. Em suma, a Administração não pode — porque sequer é facultado ao Legislativo - deixar de cumprir o núcleo essencial de um direito à prestação se este direito qualifica-se como direito fundamental. PIRES, Luis Manuel Fonseca. Controle judicial da discricionariedade administrativa: dos conceitos jurídicos indeterminados às políticas públicas. 2. ed. Belo Horizonte: Fórum, 2013. p. 268 -270. 
que deverá ser comprovada pela administração, aplicando, inclusive, a inversão do ônus da prova e, sendo comprovada a falta de previsão orçamentária, o Poder Judiciário faz constar, na próxima proposta orçamentária, verba necessária à implementação da política pública ${ }^{17}$.

É sabido que, com o elevado número de pessoas nas cidades, surgem os problemas, dentre eles a violência, malhas viárias estreitas, o desemprego em massa, o trabalho informal e a falta de moradia. Assim, não se pode imaginar a dignidade de uma pessoa que sequer tenha acesso a um lar digno, como forma de garantir o mínimo existencial, esse é entendimento de Roguet:

[...] não basta que o Estado propicie o simples habitar ao cidadão, devendo estruturar uma moradia que possibilite o desenvolvimento dos atos básicos de higiene pessoal, acesso às redes de esgoto e saneamento, área não isoladas e acessíveis com transporte público, contando com escolas e postos de saúde, como forma de garantir o mínimo existencia ${ }^{18}$.

Considerar que a moradia é um mínimo existencial, apesar de ser adequado, não é unânime, mas o teórico Marshall entendeu que o direito à moradia é mínimo Marshall:

Mas o direito básico de ter o cidadão uma moradia, seja lá qual for, é mínimo. Ele não pode reivindicar mais do que um teto sobre sua cabeça, e sua reivindicação poder ser atendida, como vimos nos últimos anos, por um cômodo num cinema abandonado transformado num centro de recuperação ${ }^{19}$.

Parte da doutrina entende que a moradia não seria um direito que pudesse ser exigido em face do Estado, ou seja, não autoriza dizer que a norma reconhece a obrigação do Estado dar uma casa a cada ser humano, esse é o pensar de Mattos:

Importa destacar, entretanto, que tal entendimento não autoriza dizer que a norma reconhece a obrigação do Estado de dar uma casa para cada indivíduo, assim como a norma estabelecida no artigo $7^{\circ}$ da Constituição não reconhece o direito subjetivo a um emprego e, sim, a criação genérica de oportunidades de trabalho e proteção ao trabalhador ${ }^{20}$.

Com o mesmo pensar, entende Souza ${ }^{21}$ que o direito de moradia não guarda relação obrigatória com o direito de propriedade, não podendo exigir do Estado um imóvel para todos:

o fato de todos terem o direito à moradia, portanto, não significa que têm o direito de exigir que o Estado dê um imóvel para todos. Não podemos jamais fazer tal afirmação. Pois o direito à moradia não guarda relação obrigatória com o direito de propriedade ${ }^{22}$

Para essa parte da doutrina, o segundo limite à interferência do Poder Judiciário é a reserva do possível como argumento contrário à concretização dos direitos fundamentais, exigindo que as pretensões formuladas em face do Estado sejam analisadas com a devida razoabilidade. Dentre as várias acepções da razoabilidade, Ávila destaca três, a primeira como equidade, a segunda similar à congruência e a terceira equiparada à equivalência:

primeiro, a razoabilidade é utilizada como diretriz que exige relação das normas gerais com as individuais do caso concreto, quer mostrando sob a qual perspectiva a norma deve ser aplicada, quer indicando em quais hipóteses o caso individual, em virtude de suas especificidades, deixa de se enquadrar na

17 GRINOVER, Ada Pellegrini. O controle das políticas públicas pelo poder judiciário. Revista do Curso de Direito da Faculdade de Humanidades e Direito, v. 7, n. 7, p. 9-37, 2010. p. 18-26.

18 ROQUET, Patrícia; CHOHFI, Roberta Dib. Políticas públicas e moradia: rumo a concretização do direito à cidade. In: SMANIO, Gianpaolo Poggio; BERTOLIN, Patrícia Tuma Mantins (Org.). O direito e as políticas públicas no Brasil. São Paulo: Atlas, 2013. p. 302-322. p. 310.

19 MARSHALL, Thomaz Humphrey. Cidadania, classe social e status. Rio de Janeiro: Zahar, 1967. p. 97.

20 MATTOS, Liana Portilho. Nova ordem jurídica-urbanística: função social da propriedade na prática dos tribunais. Rio de Janeiro: Lumen Juris, 2006. p. 79.

21 SOUZA, Sergio Iglesias Nunes de. Direito à moradia e de habilitação: análise comparativo e seu aspecto teórico e prático com os direitos da personalidade. 3. ed. São Paulo: Revista dos Tribunais, 2013. p. 165.

22 SOUZA, Sergio Iglesias Nunes de. Direito à moradia e de habilitação: análise comparativo e seu aspecto teórico e prático com os direitos da personalidade. 3. ed. São Paulo: Revista dos Tribunais, 2013. p. 165. 
norma geral. Segundo, a razoabilidade é empregada como diretriz que exige uma vinculação das normas jurídicas com o mundo ao qual se faz referência, seja reclamando a existência de um suporte empírico e adequado a qualquer ato jurídico, seja demandando uma relação congruente entre a medida adotada e o fim que ela pretende atingir. Terceiro, a razoabilidade é utilizada como diretriz que exige a relação de equivalência entre duas grandezas. ${ }^{23}$

$\mathrm{Na}$ equidade deve-se analisar o que normalmente acontece, verificando as circunstâncias do fato e o aspecto individual do caso. Já na congruência, utilizaremos o suporte empírico e a relação congruente entre o critério de diferenciação escolhido e a medida adotada. Por fim, na equivalência, utiliza-se da equivalência entre a medida adotada e o critério que a dimensiona.

Interessante é o pensar de Fonte em relação à reserva do possível, quando defende que se pode condicionar a existência de previsão orçamentária futura, incluídos na lista de precatórios:

assim, seria interessante e justo que as sentenças nesta matéria reconhecessem o direito prestacional pretendido na demanda, mesmo que fosse para condicioná-lo à existência de previsão orçamentária futura, quem sabe até incluí-los na lista de precatórios alimentares prevista no art. 100 da Constituição Federal de $1988 .^{24}$

Nessa linha de pensamento, constata-se que o fenômeno econômico tem sido invocado para impedir a concessão de direitos fundamentais sociais pelo Poder Judiciário. Alega-se, em geral, que o Poder Judiciário não pode conceder direitos cuja satisfação demandará receitas não disponíveis pelo Estado. Tal fundamento, contudo, traz em si a desconsideração de que o Estado brasileiro possui objetivos a serem, efetivamente, atendidos, de tal forma que o orçamento há de servir como instrumento para a respectiva realização e não como óbice. ${ }^{25}$

Já Pires defende que o argumento do afastamento do controle judicial com fundamento na legislação orçamentária cai por terra uma vez que a administração possuiu mais de uma opção de ação, pois sua competência não é vinculada:

não há amaras à Administração com rubricas detalhadas e minimamente precisas sobre o emprego do dinheiro público, o que representa, inclusive, a espargida liberdade discricionária de que goza o Executivo na escolha das políticas públicas e a respectiva definição dos meios.

Por isso, diante da pluralidade de opções padece o argumento que pretende afastar o controle judicial com fundamento na legislação orçamentária como se à Administração fosse conferida apenas uma única opção de ação, como se fosse uma competência vinculada. ${ }^{26}$

Para Liberati, defende-se a reserva do financeiramente possível, uma vez que não é o Estado que fixa o montante de recursos disponíveis para a concretização das ações, mas sim o legislador:

[..] no sentido de que ao estado somente poderia ser exigida a execução dos direitos sociais, se tivesse efetiva capacidade financeira para isso. Todavia, não é o Estado que fixa o montante de recursos disponíveis para a concretização das ações. Tal dever compete ao legislador, que ajusta o orçamento pretendido pelo Estado, configurando uma reserva constitucional da efetiva capacidade de prestação do Estado

\section{$[\ldots]^{27}$}

Esse argumento usado pelo Poder Público que a falta de dinheiro é um dos entraves à aplicação do direito fundamental à moradia não é adequado, uma vez que, segundo Milagres a insuficiência de fundos não pode ser causa da não efetividade desse direito:

23 ÁVILA, Humberto. Teoria dos princípios da definição à aplicaşão dos princípios jurídicos. 13. ed. São Paulo: Malheiros, 2012. p. 173.

24 FONTE, Felipe de Melo. Políticas públicas e direitos fundamentais. São Paulo: Saraiva, 2013. p. 147.

25 CANELA JUNIOR, Osvaldo. Controle judicial de políticas públicas. São Paulo: Saraiva, 2011. p. 102.

26 PIRES, Luis Manuel Fonseca. Controle judicial da discricionariedade administrativa: dos conceitos jurídicos indeterminados às políticas públicas. 2. ed. Belo Horizonte: Fórum, 2013. p. 261.

27 LIBERATI, Wilson Donizeti. Políticas públicas no estado constitucional. São Paulo: Atlas, 2013. p. 119. 
é preciso vencer essas limitações ou restrições. A ausência ou insuficiência de recursos estatais não pode ser causa da não efetividade do direito à moradia, que, pela sua essencialidade e pelo seu caráter existencial, pode ir muito além de uma concepção de direito fundamental social. ${ }^{28}$

Por outro lado, o terceiro limite à interferência do Poder Judiciário nas políticas públicas de moradia é a teoria da separação dos poderes. Ocorre que essa teoria não é absoluta, nem no que se refere ao aspecto filosófico nem em sua positivação jurídica. Assim, sobre o tema Pires entende que é possível o Judiciário intervir para recompor a ordem jurídica toda vez que for violada por ação ou omissão do Poder Público:

em suma, a divisão das funções e a distribuição destas aos diferentes órgãos nunca foi absoluta e estanque, e mesmo ao se partir da realidade positiva do nosso sistema jurídico, a independência dos Poderes reclama, em igual passo, a harmonia entre si (art. $2^{\circ}$ da Constituição Federal), o que caracteriza, nos moldes delineados pela ordem constitucional, a realização do chamado sistema de "freios e contrapesos" - isto é, e em análise do presente tema, a indiscutível possibilidade, o dever, de o Judiciário intervir para recompor a ordem jurídica toda vez que esta for violada por ação ou omissão do Executivo ${ }^{29}$.

Notamos, portanto, nova conformação do Estado por via de consectário lógico da teoria da separação dos poderes. Essa teoria não pode, evidentemente, ser um fim em si mesma e deve estar estritamente ligada às finalidades do Estado. Por conseguinte, com a alteração das finalidades estatais, altera-se igualmente a concepção da Teoria da Separação dos Poderes. A estabilidade objetiva no Estado liberal é substituída pelo dirigismo estatal, alterando-se, de forma profunda, a concepção da teoria da separação dos poderes. Dentro desse quadro, o Estado existe para atender ao bem comum, o que representa a satisfação espontânea dos direitos fundamentais. Não é possível a invocação do princípio da separação dos poderes para a não apreciação da pretensão do titular do direito fundamental social ${ }^{30}$.

Assim, detecta-se que os três limites à atuação do Poder Judiciário sobre as políticas públicas de moradia não são razoáveis, tampouco adequados, tratando-se de retórica, uma vez que, considerando que a moradia é núcleo essencial do direito fundamental, por se tratar de mínimo existencial, não pode o Estado deixar de realizar e concretizar esse direito.

\section{Possibilidade/necessidade da interferência do Poder Judiciákio nas políticas PÚBLICAS DE MORADIA INEFICAZES}

Essas políticas públicas voltadas à habitação são realizadas pelo Poder Executivo por meio dos programas de governo. Ocorre que, na falta desse poder executivo, cabe ao Poder Judiciário atuar na concretização dessas políticas públicas (judicialização da política), com a revisão das decisões e atos omissos dos demais poderes, esse é o pensar de Matsumoto "é possível e legítimo que o Poder Judiciário atue na concretização de políticas públicas, sendo também um garantidor da eficácia constitucional [...]”31

Mesmo entendendo que é preciso descobrir alternativas para se evitar a Judicialização, sem deixar os direitos desatendidos, Duarte defende que é possível a interferência do judiciário quando houver falhas nas políticas públicas:

quando houver uma falha no cumprimento desse dever, o Executivo pode ser obrigado por uma autoridade judicial a executar o que deve? Entendemos que sim, pois no Estado Social e Democrático de Direito, as políticas públicas são o objeto primário dos direitos sociais, e, na sua ausência ou insuficiência,

28 MILAGRES, Marcelo de Oliveira. Direito à moradia. São Paulo: Atlas, 2011. p. 64

29 PIRES, Luis Manuel Fonseca. Controle judicial da discricionariedade administrativa: dos conceitos jurídicos indeterminados às políticas públicas. 2. ed. Belo Horizonte: Fórum, 2013. p. 262.

30 CANELA JUNIOR, Osvaldo. Controle judicial de politicas públicas. São Paulo: Saraiva, 2011. p. $72-94$.

31 MATSUMOTO, Meggie Iara; BARBOSA, Claudia Maria. A legitimidade do poder judiciário na condução de políticas públicas para a realização de direito fundamentais. In: PAMPLONA, Danielle Anne. (Coord.). Políticas públicas: elementos para alcance do desenvolvimento sustentável. Curitiba: Juruá, 2012. p. 170. 
os indivíduos e grupos podem compelir o Estado a executar o que deve ${ }^{32}$.

Não restam dúvidas que, para efetivar os direitos fundamentais, as instituições jurídicas, órgãos e poderes do Estado podem sofrer o controle necessário, esse é o pensar de Smanio:

essa conceituação jurídica permite que as Instituições Jurídicas e os órgãos e Poderes do Estado possam efetivar as decisões Políticas e sofrer o controle necessário de sua atuação, sobretudo para assegurar os direitos fundamentais constitucionalmente estabelecidos. ${ }^{33}$

É bom frisar que a execução das políticas públicas é uma competência discricionária da administração pública que deve realizar metas presentes da Lei Maior e nas Leis Ordinárias para que se atenda o interesse público, por isso todo ato e toda atividade do Estado relacionado às políticas públicas sujeitam-se ao controle do Poder Judiciário, senão vejamos o que entende Pires:

por isso, todo ato e toda atividade da Administração Pública que realizam - ou deveriam realizar uma política sujeitam-se ao controle judicial dos seus pressupostos e/ou elementos vinculados, como competência ou sujeito, o motivo de fato, a motivação e a finalidade - e esta última conforme a teoria da finalidade. Outrossim, o espaço legítimo da discricionariedade administrativa de uma política pública deve ser aferido no âmbito normativo e no exercício da função administrativa - neste último caso, em relação ao momento de ação, à forma, aos requisitos procedimentais, à formalização, ao objeto, ao conteúdo e ao motivo. Pois o que confirma ou infirma o espaço legítimo da discricionariedade administrativa de uma política pública é o procedimento de ponderação da teoria dos princípios. ${ }^{34}$

No mesmo sentido, é o entendimento de Barroso, quando afirma que pode o judiciário impor ou invalidar ações administrativas e políticas públicas, sempre que o judiciário estiver atuando para preservar um direito fundamental:

é nesse ambiente, é nessa dualidade presente no Estado constitucional democrático que se coloca essencial: podem juízes e tribunais interferir com as deliberações dos órgãos que representam maiorias políticas isto é, o Legislativo e o Executivo - impondo ou invalidando ações administrativas e políticas públicas? A resposta será afirmativa sempre que o Judiciário estiver atuando, inequivocamente, para preservar um direito fundamental previsto na Constituição ou para dar cumprimento a alguma lei existente. Vale dizer: para que seja legítima, a atuação não pode expressar um ato de vontade própria do órgão julgador, precisando reconduzir-se a uma prévia deliberação majoritária, seja da constituição, seja do legislador. ${ }^{35}$

O equilíbrio de constitucionalidade, pois, é atingido quando o Poder Judiciário, em atividade residual e integradora, dá completude ao sistema, mediante a prolação de sentença, na qual vincula os agentes públicos à satisfação do bem da vida protegido pelo direito fundamental social. ${ }^{36}$

O Estado Social e Democrático de Direito considera alguns direitos fundamentais como deveres de ação por parte do Poder Púbico — ou pela perspectiva do administrado, como direitos a prestações, exigindo-se prestações positivas, elucida Pires:

pois é nesta dimensão dos direitos a prestações contra o Estado, que muitas vezes decorrem de direitos sociais, e outras não poucas de direitos individuais, mas que são sempre - dos direitos sociais e os direitos individuais - verdadeiros direitos fundamentais, que se apresenta de inestimável valia a teoria do núcleo essencial dos direitos fundamentais. ${ }^{37}$

32 DUARTE, Clarice Seixas. Para além da judicialização: a necessidade de uma nova forma de abordagem das políticas públicas. In: SMANIO, Gianpaolo Poggio; BERTOLIN, Patrícia Tuma Martins; BRASIL, Patrícia Cristina (Org.). O direito na fronteira das políticas públicas. São Paulo: Páginas e Letras, 2015. p. 18.

33 SMANIO, Gianpaolo Poggio. Legitimidade jurídica das políticas públicas: a efetivação da cidanania. In: SMANIO, Gianpaolo Poggio; BERTOLIN, Patrícia Tuma Mantins (Org.). O direito e as políticas públicas no Brasil. São Paulo: Atlas, 2013. p. 3-15. p. 10.

34 PIRES, Luis Manuel Fonseca. Controle judicial da discricionariedade administrativa: dos conceitos jurídicos indeterminados às políticas públicas. 2. ed. Belo Horizonte: Fórum, 2013. p. 259.

35 BARROSO, Luis Roberto. Da falta de efetividade à judicialização excessiva: direito à saúde, fornecimento de medicamentos e parâmetros para a atuação judicial. In: SOUZA NETO, Claudio Pereira de; SARMENTO, Daniel. Direitos sociais: fundamentos, judicialização e direitos sociais em espécie. Rio de Janeiro: Lumen Juris, 2010. p. 875-904. p. 882.

36 CANELA JUNIOR, Osvaldo. Controle judicial de políticas públicas. São Paulo: Saraiva, 2011. p. 96.

37 PIRES, Luis Manuel Fonseca. Controle judicial da discricionariedade administrativa: dos conceitos jurídicos indeterminados às políti- 
Já Duarte entende que as questões referentes às políticas públicas podem chegar ao Judiciário por meio de ações individuais e este pode, no caso de falhas ou desvios, aplicar o direito:

ainda que essas questões cheguem ao Judiciário por meio de ações individuais, o que deve ser apreciado é se existe uma política pública (objeto primário dos direitos sociais) em curso; se ela é adequada e suficiente; em caso negativo, qual é a razão disso; se os recursos previstos são apropriados para obtenção dos resultados pretendidos e se está havendo correta aplicação dos mesmos. Em caso de falhas ou desvios, ainda que o pedido seja individual, não se trata de fazer realocação irracional e individualista de recursos, mas de aplicar o Direito em um caso concreto de omissão ou desvio de Poder Público, o que, nos termos do artigo $5^{\circ}$, inciso XXXV, da Constituição, constitui lesão a direito e, como tal, não pode ser excluída da apreciação do Judiciário. ${ }^{38}$

Ainda sobre a possibilidade de uma ação individual para o controle das políticas públicas, explica Grinover: "qualquer tipo de ação - coletiva, individual com efeitos coletivos ou meramente individual — pode ser utilizada para provocar o Poder Judiciário a exercer o controle e a possível intervenção em políticas públicas" 39

No mesmo sentir, Roquet defende que o Juiz deve ser coautor das políticas públicas, atuando o Poder Judiciário na sua função de controle:

diante dessa nova ordem denominada 'judicialização política', contando com o juiz como coautor das políticas públicas, fica claro que sempre que os demais poderes comprometerem a integridade e a eficácia dos fins do Estado — incluindo os dos direitos fundamentais, individuais e coletivos — o Poder Judiciário deve atuar na sua função de controle.

Com efeito, se é possível controlar cada ato estatal, deve também ser possível controlar o todo e a movimentação rumo ao todo. Assim como agredir um princípio é mais grave que transgredir uma norma, empreender uma política — que é um plexo de atos — que seja em si mesma injurídica é mais grave que praticar um simples ato contrário ao Direito. ${ }^{40}$

Diferente não é o caminho de Pontes que em sua tese de doutorado defendeu a intervenção do poder judiciário nas políticas públicas:

a utilização de certos instrumentos jurídicos, bem como a provocação do Poder Judiciário, ante as decisões que se mostrem contrárias aos preceitos constitucionais, com a respectiva publicização de tais entendimentos, força, em certa medida, a evidência das manifestações de cunho meramente proprietário ${ }^{41}$.

A figura do direito público subjetivo, quando utilizada para proteger um bem que é ao mesmo tempo individual e social, deve se prestar à exigibilidade do caráter coletivo de tais direitos, ou seja, à exigibilidade de políticas públicas. No caso do direito público subjetivo, a pretensão individual é concorrente e não substitutiva em relação à pretensão pública ${ }^{42}$.

Corroborando esses entendimentos, o Supremo Tribunal Federal decidiu que pode o Poder Judiciário, em caráter excepcional, interferir na formulação e implementação das políticas públicas, sempre que comprometer a eficácia dos direitos constitucionais:

cas públicas. 2. ed. Belo Horizonte: Fórum, 2013. p. 268.

38 DUARTE, Clarice Seixas. O Ciclo das Políticas Públicas. In: SMANIO, Gianpaolo Poggio; BERTOLIN, Patrícia Tuma Mantins (Org.). O direito e as políticas públicas no Brasil. São Paulo: Atlas, 2013. p. 16-43. p. 35.

39 GRINOVER, Ada Pellegrini. O controle das políticas públicas pelo poder judiciário. Revista do Curso de Direito da Faculdade de Humanidades e Direito, v. 7, n. 7, p. 9-37, 2010. p. 35.

40 ROQUET, Patrícia; CHOHFI, Roberta Dib. Políticas públicas e moradia: a falta de acompanhamento como óbice à concretização do direito à cidade. In: SMANIO, Gianpaolo Poggio; BERTOLIN, Patrícia Tuma Martins; BRASIL, Patrícia Cristina (Org.). O direito na fronteira das politicas públicas. São Paulo: Páginas e Letras, 2015. p. 86.

41 PONTES, Daniele Regina. Direito à moradia: entre o tempo e o espaço das apropriações. 2012. Tese (Doutorado) - Universidade Federal do Paraná, Curitiba, 2012. p. 201

42 DUARTE, Clarice Seixas. Direito público subjetivo e políticas educacionais. In: BUCCI, Maria Paula Dallari (Org.). Politicas públicas: reflexões sobre o conceito jurídico. São Paulo: Saraiva, 2004. p. 113-118. p. 116-117. 
impende assinalar, no entanto, que tal incumbência poderá atribuir-se, embora excepcionalmente, ao Poder Judiciário, se e quando os órgãos estatais competentes, por descumprirem os encargos políticosjurídicos que sobre eles incidem em caráter mandatário, vierem a comprometer, com tal comportamento, a eficácia e a integridade de direitos individuais e/ou coletivos impregnados de estatura constitucional, como sucede na espécie em exame (STF, Agravo Regimental no Recurso Extraordinário n. ${ }^{\circ}$ 410.715-5)

Quanto à legitimidade para propor ação de inconstitucionalidade de políticas públicas explica Comparato:

[...] ser atribuída não apenas a órgãos estatais, como o Ministério Público e as Mesas Diretoras das Câmaras Legislativas, mas também a partidos políticos, ainda que não representados no órgão legislativo, a sindicatos ou entidades de classe, à Ordem dos Advogados do Brasil e mesmo, analogamente ao que ocorre em matéria de defesa do consumidor, a quaisquer outras organizações não-governamentais, constituídas e em funcionamento há pelo menos um ano. ${ }^{43}$

Já Barcellos defende que as políticas públicas sofrem limitações jurídicas genéricas que decorre do Estado republicano:

se a Constituição contém normas nas quais estabelecem fins públicos prioritários, e se tais disposições são normas jurídicas, dotadas de superioridade hierárquica e de centralidade no sistema, não haveria sentido em concluir que a atividade de definição das políticas públicas — que irá, ou não, realizar esses fins — deve estar totalmente infensa ao controle jurídico. Em suma: não se trata da absorção do político pelo jurídico, mas apenas da limitação do primeiro pelo segundo. E com isto chega-se à última a fazer neste ponto. (grifo no autor) ${ }^{44}$

\section{$[\ldots]$}

Assim, além da vinculação específica aos fins prioritários contidos no texto constitucional, a definição das políticas públicas e, consequentemente, do destino a ser dado aos recursos públicos, sofre limitação jurídica genérica que decorre do próprio Estado republicano. ${ }^{45}$

Por outro lado, esse pensar não é unânime, uma vez que Virgílio Afonso da Silva possui entendimento contrário, quando afirma que não podem os juízes ignorar as políticas públicas existentes, concedendo, de forma irracional e individual, medicamentos ou tratamentos:

não é possível, devido a razões que serão analisadas mais adiante, que os direitos sociais sejam tratados como se tivessem a mesma estrutura que têm os chamados direitos individuais (civis e políticos), ou seja, juízes não podem ignorar as políticas públicas já existentes nessas áreas, concedendo, de forma irracional e individualista, medicamentos, tratamentos de saúde ou vagas em sala de aula a todo aquele que recorrer ao Judiciário. ${ }^{46}$

Com o mesmo sentir, Appio, em sua tese de doutorado, posicionou-se contra a interferência do Poder Judiciário nas políticas públicas por entender que é incompatível com a democracia, uma vez que repele a atuação de instâncias não eleitas que pretendem promover seus programas próprios:

nesse sentido, o processo de formulação das políticas públicas não pode ser decorrência da vontade dos legitimados ativos para ações de controle concentrado de constitucionalidade ou ações coletivas. Aceitar que instituições específicas da comunidade organizada - em favor das quais o legislador autorizou a promoção de ações que visam proteger bens coletivos — detenham legitimidade para formular políticas públicas que vinculem os governos eleitos se revela incompatível com a concepção de democracia constitucional, a qual repele a atuação direta de instâncias não eleitas que pretendem promover seus programas próprios de ação estatal sem qualquer vinculação com a sociedade. ${ }^{47}$

43 COMPARATO, Fábio Konder. Ensaio sobre o juízo de constitucionalidade de políticas públicas. In: MELLO, Celso Antonio Bandeira de (Org.). Estudos em homenagem a Geraldo Ataliba. São Paulo: Malheiros, 1997. p. 39-48. p. 47.

44 BARCELLOS, Ana Paula. Neoconstitucionalismo, direitos fundamentais e controle das políticas públicas. Cadernos da Escola de Direito e Relações Internacionais, v. 1, n. 5, p. 125-135, jan./dez. 2005. p. 135.

45 BARCELLOS, Ana Paula. Neoconstitucionalismo, direitos fundamentais e controle das políticas públicas. Cadernos da Escola de Direito e Relações Internacionais, v. 1, n. 5, p. 125-135, jan./dez. 2005. p.135.

46 SILVA, Virgílio Afonso da. O judiciário e as políticas públicas: entre a transformação social e obstáculo à realização dos direitos sociais: In: SOUZA NETO, Claudio Pereira de; SARMENTO, Daniel (Org). Direitos sociais: fundamentos, judicialização e direitos sociais em espécie. Rio de Janeiro: Lumen Juris, 2010. p. 595.

47 APPIO, Eduardo Fernando. O controle judicial das politicas públicas no Brasil. 2004. 473 f. Tese (Doutorado) - Programa de Pós- 
Cumpre frisar que as garantias processuais — remédios jurídicos a serem exercidos perante os Tribunais — são importantes, mas não são suficientes para a satisfação dos direitos fundamentais que têm como objeto as políticas públicas. Afinal, a satisfação de uma demanda individual não resolve o problema do ponto de vista macro, levando em conta uma dimensão inerente às políticas públicas: a resolução de problemas em grande escala ${ }^{48}$.

Pelo exposto, pode-se concluir que é dever do Poder Executivo criar programas de governo para efetivar as políticas públicas de moradia, mas, no caso de omissão, não restam dúvidas que cabe ao Poder Judiciário intervir em tais políticas com o fim de concretizar esse direito fundamental.

\section{Considerações finais}

Pelo exposto, percebe-se que uma das funções do princípio da função social da propriedade urbana é se chegar à moradia, com o acesso à habitação e um lar digno, uma vez que não existe vida digna sem moradia. Para isso, um dos caminhos para a efetivação desse princípio social são as políticas públicas de moradia criadas pelo Executivo, que, quando omissas ou ineficazes, resta a atuação do Poder Judiciário, seja por meio de ações individuais ou coletivas, controlando e fiscalizando o Poder Executivo, no que se refere às políticas públicas de moradia, com o objetivo de concretizar o direito social à moradia e chegarmos a cidadania plena.

\section{REFERÊNCIAS BIBLIOGRÁfICAS}

ALEXY, Robert. Teoria dos direitos fundamentais. 2. ed. Tradução Virgílio Afonso da Silva. São Paulo: Malheiros, 2012.

ALMEIDA, Rafael Alves de. Gestão democrática na formatação de políticas públicas. 2015. 257 f. Tese (Doutorado) - Programa de Pós-Graduação em Políticas Públicas, Estratégias e Desenvolvimento, Instituto de Economia, Universidade Federal do Rio de Janeiro, Rio de Janeiro, 2015.

APPIO, Eduardo Fernando. O controle judicial das políticas públicas no Brasil. 2004. 473 f. Tese (Doutorado) Programa de Pós-Graduação em Direito, Universidade Federal de Santa Catarina, Florianópolis, 2004.

ÁVILA, Humberto. Teoria dos princípios da definição à aplicação dos princípios jurídicos. 13. ed. São Paulo: Malheiros, 2012.

BARCELLOS, Ana Paula. Neoconstitucionalismo, direitos fundamentais e controle das políticas públicas. Cadernos da Escola de Direito e Relações Internacionais, v. 1, n. 5, p. 125-135, jan./ dez. 2005.

BARROSO, Luis Roberto. Da falta de efetividade à judicialização excessiva: direito à saúde, fornecimento de medicamentos e parâmetros para a atuação judicial. In: SOUZA NETO, Claudio Pereira de; SARMENTO, Daniel. Direitos sociais: fundamentos, judicialização e direitos sociais em espécie. Rio de Janeiro: Lumen Juris, 2010. p. 875-904.

BERCOVICI, Gilberto. Planejamento e políticas públicas: por uma nova compreensão do papel do Estado. In: BUCCI, Maria Paula Dallri (Org.). Politicas Públicas: reflexões sobre um conceito jurídico. São Paulo: Saraiva, 2006. p. 143-161.

Graduação em Direito, Universidade Federal de Santa Catarina, Florianópolis, 2004. p. 421-422.

48 DUARTE, Clarice Seixas. Para além da judicialização: a necessidade de uma nova forma de abordagem das políticas públicas. In: SMANIO, Gianpaolo Poggio; BERTOLIN, Patrícia Tuma Martins; BRASIL, Patrícia Cristina (Org.). O direito na fronteira das políticas públicas. São Paulo: Páginas e Letras, 2015. p. 16. 
BONIZZATO, Luigi. Propriedade urbana privada e direitos sociais. Curitiba: Juruá, 2007.

BUCCI, Maria Paula Dallari. Fundamentos para uma teoria jurídica de políticas públicas. São Paulo: Saraiva, 2013.

BUCCI, Maria Paula Dallari. O conceito de política pública em direito. In: (Org.). Politicas Públicas: reflexões sobre o conceito jurídico. São Paulo: Saraiva, 2006. p. 25-27.

BUCCI, Maria Paula Dallari. Quadro de referência de uma política pública: primeiras linhas de uma visão jurídico-institucional. In: SMANIO, Gianpaolo Poggio; BERTOLIN, Patrícia Tuma Mantins; BRASIL, Patricia Cristina (Org.). O direito na fronteira das políticas públicas. São Paulo: Páginas e Letras, 2015.

CAFRUNE, Eibs Marcelo. Mediação de conflitos fundiários urbanos: do debate teórico à construção política. Revista da Faculdade de Direito da UniRitter, Porto Alegre, n. 11, p. 197-217, 2010.

CANELA JUNIOR, Osvaldo. Controle judicial de políticas públicas. São Paulo: Saraiva, 2011.

CARVALHO, José Murilo de. Cidadania no Brasil: o longo caminho. 3. ed. Rio de Janeiro: Civilização Brasileira, 2002.

COMPARATO, Fábio Konder. Ensaio sobre o juízo de constitucionalidade de políticas públicas. In: MELLO, Celso Antonio Bandeira de (Org.). Estudos em homenagem a Geraldo Ataliba. São Paulo: Malheiros, 1997. p. 39-48.

COMPARATO, Fábio Konder. Estado, reforma e desenvolvimento: a nova cidadania. Lua Nova: Revista de Cultura e Política, São Paulo, n. 28-29, p. 1-11, abr. 2008.

DIMOULIS, Dimitri; MARTINS, Leonardo. Teoria geral dos direitos fundamentais. 4. ed. São Paulo: Atlas, 2012.

DUARTE, Clarice Seixas. Direito público subjetivo e políticas educacionais. In: BUCCI, Maria Paula Dallari (Org.). Políticas públicas: reflexões sobre o conceito jurídico. São Paulo: Saraiva, 2004. p. 113-118.

DUARTE, Clarice Seixas. O Ciclo das Políticas Públicas. In: SMANIO, Gianpaolo Poggio; BERTOLIN, Patrícia Tuma Mantins (Org.). O direito e as políticas públicas no Brasil. São Paulo: Atlas, 2013. p. 16-43.

DUARTE, Clarice Seixas. Para além da judicialização: a necessidade de uma nova forma de abordagem das políticas públicas. In: SMANIO, Gianpaolo Poggio; BERTOLIN, Patrícia Tuma Martins; BRASIL, Patrícia Cristina (Org.). O direito na fronteira das políticas públicas. São Paulo: Páginas e Letras, 2015.

ECO, Humberto. Como se faz uma tese. 14. ed. São Paulo: Perspectiva, 1998.

FIGUEIREDO, Leonardo Vizeu. Lições de direito econômico. 7. ed. Rio de Janeiro, 2014.

FONTE, Felipe de Melo. Políticas públicas e direitos fundamentais. São Paulo: Saraiva, 2013.

FREITAS, Igor Vilas Boas. Avaliação de política pública no Senado Federal: proposta de abordagem. Brasília: Senado Federal, 2013. Disponível em: <https://www12.senado.leg.br/publicacoes/estudos-legislativos/ tipos-de-estudos/outras-publicacoes/avppsf/avaliacao-de-politicas-publicas-no-senado-federal-1>. Acesso em 10 set. 2015.

FUNDAÇÃO JOÃO PINHEIRO. Déficit Habitacional no Brasil: 2011-2012. Belo Horizonte, 2015.

GRINOVER, Ada Pellegrini. O controle das políticas públicas pelo poder judiciário. Revista do Curso de Direito da Faculdade de Humanidades e Direito, v. 7, n. 7, p. 9-37, 2010.

HERRERA, Carlos Miguel. Estado, constitución y derechos sociales. Revista Derecho del Estado, n. 15, p. 7592, dic. 2003.

LIBERATI, Wilson Donizeti. Políticas públicas no estado constitucional. São Paulo: Atlas, 2013. 
LOPES, Ana Maria D’Ávila. A cidadania na constituição brasileira de 1988: redefinindo a participação política. In: BONAVIDES, Paulo; LIMA, Francisco Gérson Marques; BEDÊ, Faya Silveira (Org.). Constituição e processo: estudos em homenagem a Prof. J. J. Canotinho. São Paulo: Malheiros, 2006. p. 21-33.

MACEDO FILHO, Renato. Onde mora a cidadania? Visibilizando a participação das mulheres no movimento sem teto. 2010. Tese (Doutorado) - Universidade Federal de Salvador, Salvador, 2010.

MARMELSTEIN, George. Curso de direitos fundamentais. 3. ed. São Paulo: Atlas, 2011.

MARSHALL, Thomaz Humphrey. Cidadania, classe social e status. Rio de Janeiro: Zahar, 1967.

MASCARO, Alysson Leandro. Crítica da legalidade e do direito brasileiro. 2. ed. São Paulo: Quartier Latin, 2008.

MATSUMOTO, Meggie Iara; BARBOSA, Claudia Maria. A legitimidade do poder judiciário na condução de políticas públicas para a realização de direito fundamentais. In: PAMPLONA, Danielle Anne (Coord.). Políticas públicas: elementos para alcance do desenvolvimento sustentável. Curitiba: Juruá, 2012.

MATTOS, Liana Portilho. Nova ordem jurídica-urbanistica: função social da propriedade na prática dos tribunais. Rio de Janeiro: Lumen Juris, 2006.

MILAGRES, Marcelo de Oliveira. Direito à moradia. São Paulo: Atlas, 2011.

MONEBHURRUN, Nitish. Manual de metodologia jurídica: técnicas para argumentar em textos jurídicos. São Paulo: Saraiva, 2015.

MUKAI, Toshio. Temas de direito urbanistico e ambiental. Belo Horizonte: Fórum, 2007.

PIRES, Luis Manuel Fonseca. Controle judicial da discricionariedade administrativa: dos conceitos jurídicos indeterminados às políticas públicas. 2. ed. Belo Horizonte: Fórum, 2013.

PONTES, Daniele Regina. Direito à moradia: entre o tempo e o espaço das apropriações. 2012. Tese (Doutorado) - Universidade Federal do Paraná, Curitiba, 2012.

RIBEIRO, Hélcio. Constituição, Participação e Políticas Públicas. In: SMANIO, Gianpaolo Poggio; BERTOLIN, Patrícia Tuma Mantins (Org.). O direito e as políticas públicas no Brasil. São Paulo: Atlas, 2013. p. 44-62.

RIZZO JUNIOR, Ovidio. Controle social de políticas públicas. 2009. Tese (Doutorado) - Faculdade de Direito da USP, São Paulo, 2009.

ROQUET, Patrícia; CHOHFI, Roberta Dib. Políticas públicas e moradia: a falta de acompanhamento como óbice à concretização do direito à cidade. In: SMANIO, Gianpaolo Poggio; BERTOLIN, Patrícia Tuma Martins; BRASIL, Patrícia Cristina (Org.). O direito na fronteira das políticas públicas. São Paulo: Páginas e Letras, 2015.

ROQUET, Patrícia; CHOHFI, Roberta Dib. Políticas públicas e moradia: rumo a concretização do direito à cidade. In: SMANIO, Gianpaolo Poggio; BERTOLIN, Patrícia Tuma Mantins (Org.). O direito e as políticas públicas no Brasil. São Paulo: Atlas, 2013. p. 302-322.

RUFINO, Maria Beatriz Cruz; SHIMBO, Lúcia Zanin; AMORE, Caio Santo (Org.). Minha casa... e a cidade? avaliação do programa minha casa minha vida em seis estados brasileiros. Rio de Janeiro: Letra capital, 2015.

SARLET, Ingo Wolfgang. A eficácia dos direitos fundamentais: uma teoria geral dos direitos fundamentais na perspectiva constitucional. 10. ed. Porto Alegre: livraria do Advogado, 2010.

SEVERINO, Antônio Joaquim. Metodologia do trabalho científico. 22. ed. São Paulo: Cortez, 2007.

SILVA, Solange Teles. Direito fundamental ao meio ecologicamente equilibrado: avanços e desafios. Revista de Direito Ambiental, v. 48, p. 224-247, 2007. 
SILVA, Virgílio Afonso da. O judiciário e as políticas públicas: entre a transformação social e obstáculo à realização dos direitos sociais: In: SOUZA NETO, Claudio Pereira de; SARMENTO, Daniel (Org). Direitos sociais: fundamentos, judicialização e direitos sociais em espécie. Rio de Janeiro: Lumen Juris, 2010. p. 875-904 SMANIO, Gianpaolo Poggio. As dimensões da cidadania. Revista da ESMP, v. 2, p. 13-23, jan./jun. 2009.

SMANIO, Gianpaolo Poggio. Cidadania e políticas públicas. In: ; BERTOLIN, Patrícia Tuma Mantins; BRASIL; Patricia Cristina (Org.). O Direito na Fronteira das Politicas Públicas. São Paulo: Páginas e Letras, 2015.

SMANIO, Gianpaolo Poggio. Legitimidade jurídica das políticas públicas: a efetivação da cidanania. In: SMANIO, Gianpaolo Poggio; BERTOLIN, Patrícia Tuma Mantins (Org.). O direito e as políticas públicas no Brasil. São Paulo: Atlas, 2013. p. 3-15.

SOUZA, Celina. Políticas públicas: uma revisão da literatura. Revista Sociologias, Porto Alegre, v. 8, n. 16, p. 20-45, jul./dez. 2006.

SOUZA, Luciane Moessa de. Meios consensuais de solução de conflitos envolvendo entes públicos e a mediação de conflitos coletivos. 2010. Tese (Doutorado) - Faculdade Federal de Santa Catarina, Florianópolis, 2010.

SOUZA, Sergio Iglesias Nunes de. Direito à moradia e de habilitação: análise comparativo e seu aspecto teórico e prático com os direitos da personalidade. 3. ed. São Paulo: Revista dos Tribunais, 2013. 
Para publicar na revista Brasileira de Políticas Públicas, acesse o endereço eletrônico www.rbpp.uniceub.br

Observe as normas de publicação, para facilitar e agilizar o trabalho de edição. 